\title{
DOS QUADROS DE MONET AOS PATOS DA MARGARIDA - DIVAGAÇÕES SOBRE INVESTIGAÇÃO FENOMENOLÓGICA
}

\author{
From Monet's Paintings to Margaret's Ducks. Divagations on Phenomenological Research \\ De las Pinturas de Monet a los Patos de Margarida. Divagaciones acerca de la \\ Investigación Fenomenológica
}

Daniel Cunha Monteiro De Sousa

\begin{abstract}
Resumo: Este artigo aborda aspectos relacionados com a aplicação da fenomenologia à área da investigação. Foca em particular alguns aspectos, presentes na literatura, que o autor considera como não consensuais. Apontam-se razões para haver uma explicitação dos princípios fenomenológicos e das aplicações destes ao contexto da investigação. Defende-se um aprofundamento das metodologias de investigação fenomenológicas existentes, em contraponto à promoção de um número ilimitado de metodologias, actualmente em voga em investigação qualitativa. Refere-se ainda a importância de reflectir sobre a noção de método e de clarificar as diferenças existentes entre filosofia, psicologia e psicoterapia, no âmbito da aplicação do método fenomenológico. Palavras-chave: Método Fenomenológico; Psicoterapia; Fenomenologia; Investigação Qualitativa.
\end{abstract}

\begin{abstract}
This paper deals with a number of aspects related to the application of phenomenology in the area of research. It focuses particularly on some aspects, present in some literature, that the author considers as non-consensual. A number of reasons are propounded to explain the phenomenological principles and application of these within the context of research. The strengthening of the available methodologies of phenomenological research is upheld, as a counterpoint to the fostering of an unlimited number of methodologies currently in fashion in qualitative research. The importance of reflecting on the concept of method is also referred to as well as that of clarifying the differences existent between philosophy, psychology and psychotherapy within the scope of the application of the phenomenological method.

Keywords: Phenomenological Method; Psychotherapy; Phenomenology; Qualitative Research.

Resumen: Este artículo aborda los aspectos relacionados a la aplicación de la fenomenología en el área de la investigación. Enfoca en particular, algunos aspectos presentes en la literatura, que el autor considera como consensuales. Se señalan las razones para que haya una explicitación de los principios fenomenológicos y de las aplicaciones de estos al contexto de la investigación. Se defiende el profundizar las metodologías de investigación fenomenológicas existentes, en contraposición a la promoción de un número ilimitado de metodologías, actualmente en boga en la investigación cualitativa. También se refiere a la importancia de reflexionar sobre la noción del método y de esclarecer las diferencias existentes entre la filosofía, la psicología y la psicoterapia, en el ámbito de la aplicación del método fenomenológico.

Palabras-clave: Método Fenomenológico; Psicoterapia; Fenomenología; Investigación Cualitativa.
\end{abstract}

\section{Introdução}

Comecemos pelas razões que nos conduziram a este texto. Recentemente, participamos nuns encontros, onde foram debatidos alguns autores e suas propostas de aplicação do método fenomenológico (Colaizzi, 1978; Giorgi, 1985; Karlsson, 1995; Moustakas, 1994; van Kaam, 1966; van Manen, 1990). Dos debates emergiram todo um conjunto de ideias e opiniões, umas consensuais, outras divergentes. Estes encontros tiveram um carácter privado, no entanto, pareceu evidente que a discussão sobre as diferentes aplicações do método fenomenológico, deveria ser estendida a um âmbito mais alargado, com eventuais repercussões positivas para estudantes, investigadores, professores, clínicos.

O objectivo deste texto não é o preencher essa lacuna ou realizar um resumo sobre as idéias apresentadas nos encontros referidos. Queremos apenas debruçarmo-nos sobre algumas questões que nos parecem menos consensuais. Há, no entanto, uma questão transversal que irá acompanhar as temáticas exploradas neste texto. Surgiu, durante esses encontros, a hipótese de estarmos a defender uma visão monoteísta do método fenomenológico. Defendemos entusiasticamente que a fenomenologia, enquanto método de investigação, se afirme cada vez mais no panorama internacional da investigação qualitativa. Também é verdade que temos algumas reservas da forma como a fenomenologia é usada actualmente como instrumento de investigação. No entanto, não pensamos haver uma maneira única e ajustada de aplicar a fenomenologia à investigação.

Não é tanto a hipótese referida - a defesa de uma visão singular do método - que acaba por ser importante, mas o que nela está subjacente, o que pode espelhar sobre algu- 
mas das controvérsias que possamos partilhar, enquanto comunidade que partilha um interesse comum - a fenomenologia. A hipótese, que nos pareceu ser um equívoco, acabou por se transformar em catalisador.

Naturalmente que as questões relacionadas com a aplicação do método fenomenológico são imensas e estão muito para além do âmbito deste texto. Iremos enumerar alguns aspectos que, diríamos, são consensuais e clarificam a posição da fenomenologia enquanto modelo de investigação. Seguidamente, quatro pressupostos presentes em alguma da literatura, finalmente, tentaremos expor breves reflexões sobre os mesmos.

\section{Investigação fenomenológica}

Pretendemos ser breves a enumerar alguns dos pressupostos da investigação fenomenológica. Esse trabalho tem sido elaborado por diferentes autores, por exemplo, muito recentemente, Spinelli (2006) clarificou as características e os pressupostos fundamentais da fenomenologia quando aplicada à investigação. Sintetizamos alguns dos aspectos tidos como consensuais.

O primordial objecto de estudo da investigação fenomenológica é o sentido da experiência vivida das pessoas que estão impreterivelmente ligados ao mundo que, por sua vez, se traduz numa rede social e cultural co-construída. Ao contrário de outros modelos, faz uso de um aspecto fundamental para poder estudar os fenômenos humanos: o contexto.

Por outro lado, a fenomenologia não pretende seguir uma epistemologia empírica, na qual o modelo de causalidade é considerado como único adequado, para alcançar um conhecimento cientificamente válido. A fenomenologia tem como referencial fundamental a noção de que a consciência é intencional, i.e., a consciência é sempre consciência de algo e que o objecto visado transcende sempre o acto de consciência intencional pelo qual é visado. Trata-se de uma visão distinta da perspectiva naturalista da psicologia.

Por estas razões a fenomenologia apresenta-se como uma alternativa qualitativa de investigação, não se centrando na quantificação dos resultados. O investigador é tido como sendo um observador participante, que procura compreender e explicitar o sentido da experiência dos fenômenos humanos, usando para isso metodologias essencialmente descritivas e hermenêuticas. O investigador fenomenológico não é um técnico distante e independente que analisa e sintetiza repetições determinadas e idênticas. Muito sucintamente, estas são algumas premissas que poderíamos considerar como sendo consensuais sobre a investigação fenomenológica. É ainda pacífico considerar-se que não há uma única forma correcta de realizar investigação fenomenológica.

\section{Alguns aspectos não consensuais da investigação fenomenológica}

Passamos a enumerar apenas quatro pressuposições que, arriscaríamos afirmar, não são consensuais, como as acima mencionadas:

- Desenvolver investigação fenomenológica é fazer filosofia;

- Há um número ilimitado de maneiras de desenvolver desenhos metodológicos de investigação fenomenológica;

- Usar a noção de método numa investigação fenomenológica é em si mesmo contraditório com a fenomenologia;

- Realizar investigação fenomenológica é o mesmo que desenvolver terapia existencial.

Estes são alguns exemplos, outros poderiam ser apresentados, defendidos por alguns autores e criticadas por outros, não merecendo um consenso fácil. Assumindo não haver unanimidade, algumas perguntas poderiam ser acrescentadas:

- Quais os critérios para se considerar que um estudo é fenomenológico?

- Quais são os limites que, aos serem ultrapassados, implicam que a investigação seja considerada fora do âmbito da fenomenologia?

- Em que argumentos nos baseamos para decidir esses critérios?

\section{Deambulações por entre Pinturas e Patos}

\section{Realizar investigação fenomenológica é o mesmo que desenvolver terapia existencial}

Relativamente a este ponto (realizar investigação fenomenológica é o mesmo que desenvolver terapia existencial), poderíamos lembrar Casement (1985) quando afirma que o espaço terapêutico é, por excelência, um "research space" onde emergem as dinâmicas da relação terapêutica. De facto, a psicoterapia em sentido lato, poderá ser entendida como um espaço-tempo, onde as pessoas constroem sentido para as suas vivências. Em particular, a psicoterapia existencial, postula a necessidade de terapeuta e cliente, se posicionarem de uma forma onde a relação terapêutica se torna, no essencial, numa investigação, numa exploração e clarificação do nosso ser no mundo.

Spinelli (2006), apresentou argumentos cruciais que demonstram as semelhanças entre a terapia existencial e a investigação em ciências humanas. Há um aspecto fundamental que realça melhor do que qualquer outro, essa afinidade: "the inter-relatedness as the foundational value upon which any human and humane form of enquiry must rest”. É assim inegável o valor acrescido que poderemos 
ter em relacionar a terapia existencial e as suas características com a investigação em ciências humanas.

No entanto, o argumento parece ser essencialmente epistemológico, i.e., a forma como produzimos conhecimento em ciências humanas e em terapia existencial, passa sobretudo pela arena inter-relacional. Assumindo este argumento como sendo "pivot" e epistemológico, o que se passará quando estivermos ao nível metodológico? Poderemos considerar que boas práticas terapêuticas são estratégias adequadas de investigação? Dependendo do tópico, da pergunta de investigação colocada pelo investigador, como definir o adequado desenho metodológico? Seguindo uma sensibilidade terapêutica ou um rigor metodológico? Provavelmente, tentando relacionar ambas.

Mas, tal como se pode adequar a terapia a um determinado cliente e às suas especificidades, tal como pode ser necessário haver uma flexibilidade por parte do terapeuta, para fechar um contrato terapêutico que sirva tanto ao terapeuta, como ao cliente, parece que é igualmente necessário que o investigador possa considerar a possibilidade que uma investigação necessite de um desenvolvimento que cumpra determinados passos, que não aqueles que o terapeuta seguiria numa viagem de investigação com um determinado cliente. Por vezes, a perspectiva do terapeuta poderá ser adequada, outras, nem por isso.

Apesar de haver um "know-how" do terapeuta que pode ajudar a desenvolver pesquisa, por exemplo, a situação de entrevista como recolha de dados, muito habitual em investigação qualitativa, é um exemplo típico onde as capacidades interpessoais do terapeuta poderão ser realçadas. Parece-nos no entanto, haver a necessidade de desenvolver e promover um saber próprio e específico, relacionado com o campo da investigação, distinto do campo terapêutico. Aquilo que expressamos que surge como evidente, torna-se num tópico de reflexão importante.

As fronteiras que separam hoje terapia e investigação tendem a ser ténues. A nossa questão é simples: pode haver semelhanças fundamentais entre terapia existencial e investigação em ciências humanas, no entanto, este aspecto não nos deve impedir de explicitar quais são as limitações de extrapolar uma dada realidade, (desenvolver terapia), com outra que é diferente e que tem um setting igualmente diferente (produzir investigação). Este é um argumento que nos leva a defender a necessidade de promover um aumento de seminários dedicados à investigação, em programas de formação de terapeutas.

\section{Desenvolver investigação fenomenológica é fazer filosofia}

Quanto ao primeiro ponto (fazer investigação fenomenológica é fazer filosofia) - discordamos. A fenomenologia nasceu de um movimento filosófico. Obviamente, pode-se desenvolver investigação fenomenológica de cariz filosófico, diria mesmo, que essa é sua base mais natural. No entanto, não nos parece que produzir investigação feno- menológica, em psicoterapia e em psicologia, tenha necessariamente de ser considerada como uma pesquisa filosófica. Como nos disse um fenomenólogo da área da filosofia, a fenomenologia, como área disciplinar estrita, depressa se transforma numa escolástica e se torna estéril.

É pela construção de um diálogo com outras áreas do saber que a fenomenologia se poderá melhor desenvolver, reconhecer-se a si mesma, não promovendo áreas estanques entre si e outras disciplinas, mas co-construindo a forma de ver o mundo. Trata-se de um convite para um trabalho comum. A filosofia, a psicologia e a psicoterapia são áreas distintas. As inter-relações que possam existir entre estas não estão previamente definidas, pré-demarcadas, pelo contrário, estão em aberto e solicitam uma intervenção conjunta. Há espaços em aberto por construir.

Acreditamos que é exactamente pelo facto de haver diferenças entre a fenomenologia e outras áreas de saber, como a psicoterapia, que permite a construção de um conhecimento fértil e frutuoso. Não através de uma colagem imediata, ou sem se proceder a um escrutínio rigoroso da aplicação de conceitos, de uma determinada área para outra. Esta é aliás, uma das razões, ao contrário de muitos autores, porque sugerimos a necessidade de haver uma mediação entre a aplicação da fenomenologia à psicoterapia, na qual a psicologia (fenomenológica) poderá desempenhar um papel importante.

Transposições imediatas, de uma área do saber para outra, trazem menos vantagens do que um esforço de discussão e diálogo, desde que seja assumido que de facto estamos a falar de áreas distintas. E poderemos facilmente perceber que se tratam de áreas distintas. A identificação de uma determinada actividade realiza-se, através do reconhecimento da tradição e da comunidade onde esta se insere. A fenomenologia enquanto actividade filosófica, a psicologia fenomenológica e a terapia existencial, estão cada uma delas, inseridas nas suas próprias tradições e comunidades, distintas entre si, com problemáticas próprias, com audiências específicas, com linguagens inerentes a cada área.

Poderíamos ainda acrescentar o nível institucional. Todas as áreas do saber se desenvolvem através da criação de instituições onde a dimensão política de toda a acção humana se realça, da melhor e pior maneiras. Os trabalhos de Focault, realçam magistralmente, a interligação dos conhecimentos acadêmicos e científicos com os poderes institucionais e políticos. Em resumo, regressando ao ponto inicial, diríamos que ao produzir investigação em psicoterapia, deveríamos ter em conta que estamos efectivamente a produzir investigação em psicoterapia, aplicando o método fenomenológico, o que não é, repetimos, necessariamente o mesmo, de estar a desenvolver pesquisa filosófica.

3. Há um número ilimitado de maneiras de desenvolver desenhos metodológicos de investigação fenomenológica; 


\section{Usar a noção de método numa investigação feno- menológica é em si mesmo contraditório com a fenomenologia;}

Gostaríamos agora de apresentar alguns argumentos sobre dois aspectos atrás mencionados como não consensuais: há um número ilimitado de maneiras de desenvolver desenhos metodológicos de investigação fenomenológica e; usar a noção de método numa investigação fenomenológica é, em si mesmo, contraditório com a fenomenologia. Mais uma vez, são duas questões fascinantes e muito extensas que não podem ser apropriadamente debatidas num espaço tão curto, permitindo apenas partilhar algumas pistas para discussão.

Uma maneira célere, eficaz e legítima de nos posicionarmos em relação à primeira questão, é seguir a sugestão de Hans Gadamer (1960/2003; 1976), ou seja, desvalorizando a própria noção de método, muito dependente de uma visão científica e racionalista. Em contraponto, sobrepor uma outra perspectiva, onde se salientam aspectos da vida quotidiana, de que a arte a cultura são exemplos, como espaços de excelência de investigação. Espaços onde o homem se pode ir conhecendo de forma situada, local e temporalmente, em permanência. Com Gadamer (1960/2003; 1976), como aliás com Dilthey, Husserl, Heidegger, Ricoeur - embora estes autores não partilhem visões semelhantes - são valorizados dois aspectos fundamentais. A dimensão histórica, o homem ao compreender-se, fá-lo em diálogo com uma tradição préexistente, e a dimensão existencial, o homem é um agente, interveniente e activo na construção dessa compreensão e na forma como elabora as suas interpretações.

Mais radicalmente, poderemos seguir Feyerabend (1975) que na obra "Against the Method", contestou a presunção do conhecimento científico deter o privilégio de ser um saber superior e, sobretudo, demonstrou que, por vezes, novas descobertas ou o surgimento de novos conhecimentos, são alcançados porque, precisamente, foram transgredidas as regras metodológicas vigentes. Todas as regras metodológicas têm limites, por vezes, terão de ser violadas, no entanto, esta posição não implica defender que as regras metodológicas não são importantes ou que não devam ser seguidas. O que Feyerabend (1975) demonstrou com clareza, foi a ineficácia do uso de um único método universal, que pudesse ser aplicado a qualquer fenômeno de estudo.

Não se trata apenas de defender que, regras e procedimentos não ajudam investigadores a produzir bons resultados, por vezes assim acontece, mas de salientar igualmente que essas mesmas regras, em determinadas investigações produzem fracassos redundantes. Segundo o autor, é necessário desenvolver uma abordagem contextual, não para substituir regras absolutas, mas para as complementar. O próprio acto metodológico pode demonstrar a necessidade de colocar em causa as premissas metodológicas.
No entanto, isto não significa defender uma posição de "anything goes". O "anarquismo epistemológico", como expressou Feyerabend (1975), não é uma pura rejeição da utilidade de regras metodológicas ou a defesa de que qualquer desenho metodológico é válido, mas a constatação que a metodologia usada, não deve permanecer invariável face à diversidade das situações de pesquisa e dos fenômenos a estudar, bem como, perante as condições históricas nas quais, qualquer investigação, está inserida.

Alguns autores defendem que Feyerabend (1975) desviou a epistemologia para a retórica. A metodologia adoptada estaria assim dependente da coerência interna dos argumentos apresentados pelo investigador, da validade dos mesmos, discutida dentro da comunidade onde se insere o investigador, do rigor dos passos metodológicos, de uma exigência de consistência entre os dados e os resultados, entre outros aspectos.

No caso do método fenomenológico, assumimos a preocupação de podermos estar a cair numa situação de "anything goes". Várias razões contribuem para este cenário. Comecemos por alguns pontos aparentemente menores, mas nem por isso, menos importantes. A fenomenologia, como é sabido, tem a sua fonte na filosofia. Mas a fonte não é unívoca, pelo contrário. Vários autores da filosofia defendem visões distintas sobre a fenomenologia. Diríamos mesmo que uma das características da fenomenologia tem sido o seu contínuo movimento, num permanente reescrever, através do tempo e da pena de diferentes autores. Transpor essas visões dissemelhantes, para outras áreas de conhecimento, como a investigação ou a psicoterapia, resulta muitas vezes num conjunto de equívocos.

Outro aspecto gerador de confusão, prende-se como a maneira como hoje se escreve e comunica sobre fenomenologia. $\mathrm{O}$ facto de um determinado autor se referir à fenomenologia não significa que esteja a abordar a fenomenologia tal como entendida pelo leitor. Em si mesmo isto não é um problema. $\mathrm{O}$ que pode constituir um obstáculo grave, é escrevermos actualmente sobre fenomenologia, não sendo claros e rigorosos, sobre os conceitos que usamos e estes não estarem de acordo com as formulações de autores que citamos.

Este aspecto, relaciona-se, com um outro que deveria merecer uma atenção mais cuidada: a proliferação de fontes secundárias. Referimo-nos a uma imensa quantidade de literatura (livros, teses, artigos) que é pública, supostamente exigente, mas que quando analisada com atenção, verifica-se que os autores podem, por exemplo, abordar a fenomenologia hermenêutica de Heidegger (1927/1962), sem nunca terem lido Heidegger, baseando-se apenas noutros autores que, supostamente, terão lido Heidegger. $\mathrm{O}$ que se afirmou de Heidegger aplica-se a outros autores e temáticas da área. No âmbito das ciências sociais e humanas, a fenomenologia é mencionada e reclamada pelos mais variados autores, mas de forma incipiente e sem o rigor desejado. 
The Interpretative Phenomenological Analysis (Smith \& Osborn, 2003), apresenta as suas bases teóricas em duas páginas. Nestas, é referido que o "IPA is therefore intellectually connected to hermeneutics and theories of interpretation" but add that "different interpretative stances are possible, and IPA combines an empathic hermeneutics with a questioning hermeneutics". O autores continuam afirmando que o "IPA also acknowledges a debt to symbolic interactionism", mas mais ainda, "IPA has a theoretical commitment to the person as a cognitive, linguistic, affective and physical being (...) and this suggests an interesting theoretical alliance with the cognitive paradigm that is dominant in contemporary psychology".

No nosso entender, os autores "conjugam" diferentes perspectivas teóricas, não clarificam o que significam cada um dos conceitos referidos e não explicam como podem ser articulados em conjunto, como corpo teórico de uma metodologia de investigação. Carla Willing (2001) analisou o IPA e interrogou-se se este deveria ser considerado genuinamente fenomenológico, concluindo, entre outros aspectos, "that genuinely phenomenological research should not study people's cognitions; instead, it should aim to understand lived experience”. Muito poderia ser dito sobre as propostas teóricas do IPA, poderíamos questionar se a sua denominação não ficaria mais correcta como "Integrative Interpretative Analysis". O mais importante é o exemplo demonstrar a necessidade de se clarificar conceitos, explicitar a sua articulação, demonstrar coerência entre princípios e aplicação prática.

Como é sabido, uma pesquisa conduzida correctamente, terá de demonstrar um equilíbrio entre o nível ontológico, o nível epistemológico e o nível metodológico. Incoerências entre estas dimensões, poderão resultar em graves consequências, promovendo mais uma desinformação dos investigadores e não uma adequada melhoria do conhecimento.

Outro aspecto que contribui para este contexto, prende-se com o cenário mais alargado da investigação qualitativa. A investigação qualitativa em geral, e a perspectiva fenomenológica em particular, estão ainda numa fase muito imatura do seu crescimento, porventura, não atingiram a fase de adolescência. Como reflexo dessa situação estão a experimentar os seus limites. Estão numa fase rebelde de pretender demonstrar aos outros que há sempre outras maneiras de fazer as coisas - a sua própria maneira.

Desta situação, emergem um sem número de maneiras distintas de usar o método fenomenológico, quase ilimitadas, como se cada autor pretendesse apresentar o seu próprio método. Hoje, na investigação qualitativa, promove-se mais a legitimidade em cada investigador apresentar o seu método, do que em investir num aprofundamento e numa melhoria das propostas metodológicas já existentes.

É sobretudo este aspecto que questionamos frontalmente.
Como referido, na linha de Feyerabend (1975), preconizar uma variedade de procedimentos não significa fomentar o surgimento de metodologias avulso. Mais ainda, o argumento não é apenas quantitativo, pelo contrário, a interrogação que se coloca é de saber se é a livre multiplicação de metodologias distintas que melhor poderá assegurar a produção e a descoberta de novos conhecimentos. Esta é que é a questão. No nosso entender, o facto de estarmos confinados a um determinado espaço (método) não é necessariamente sinónimo de perda de liberdade (criatividade na investigação). Pelo contrário, julgamos mesmo que a criação de limites (passos metodológicos), obriga o investigador a elaborar e pôr em prática a sua capacidade criativa e de produzir conhecimento inter subjectivo.

Poderíamos, também, esboçar uma analogia com o espaço terapêutico. Não raras vezes, os terapeutas ouvem os seus clientes dizerem que a única coisa que os poderia ajudar era "mudarem de vida", ou "iniciar tudo de novo", ou ainda, "só se mudasse para outro país, onde poderia recomeçar do zero". Os terapeutas sabem que, precisamente, é pelo facto do consultório se constituir, paradoxalmente, como um espaço de limites e, simultaneamente de liberdade, no sentido que reflecte e é exemplo do mundo de "lá de fora", que a terapia acaba, por vezes, por proporcionar transformações, no sentido do cliente poder re-pensar a sua existência e forma de ser.

Permitam-nos seguir o conselho de Gadamer (1960/2003; 1976) e apresentar dois exemplos da vida corrente. Um primeiro, que nos surgiu de rompante, relaciona-se com algumas das pinturas de Claude Monet. O pintor impressionista, adoptou ao longo da sua vida, o princípio de explorar incessantemente em tela o mesmo tema, o mesmo objecto, do mesmo ângulo, embora em diferentes alturas do dia, com diferentes tonalidades de luz, que produziam diferentes colorações.

Disso são exemplo a série de pinturas da Catedral de Rouen. Monet, seguia assim uma matriz de base invariável, pintava o mesmo objecto do mesmo ângulo, no entanto, circunscrito a esse limite, produzia a diferença do olhar, deixava escorrer o acaso da pincelada, demarcava na tela fixa e rígida, a fluidez perceptiva, a fugacidade da tonalidade e da temperatura da luz. O que pretendia o nosso pintor? Ser rigorosamente metódico e objectivo? Monet foi objectivamente subjectivo. Procurou, dentro dos limites de um mesmo espaço, na representação sistemática do mesmo tema, demonstrar e salientar a subjectividade do olhar humano. Não fará o investigador o mesmo?

A utilização de uma mesma metodologia de investigação, de passos sistemáticos e rigorosos, aplicada a diferentes contextos de investigação, significa que produzirá resultados menos importantes ou que dê menor relevância à subjectividade e à criatividade do investigador e dos conhecimentos por este elaborados? A justiça ao estudo dos fenômenos humanos só poderá ser feita se aceitarmos a proliferação ilimitada de metodologias de investigação? 
Usar um método em investigação fenomenológica é um contra-senso? Não cremos.

Criar limites é ajudar a crescer, como quem diz, a descobrir. Mais importante é recordar novamente com Feyerabend (1975), o erro em que caímos ao criar dicotomias nas discussões metodológicas, entre os contextos de justificação e descoberta. Se a ciência, ou se quisermos a produção de conhecimento, se realizasse apenas por procedimentos de justificação, seria conduzi-la a um auto anulamento. É a interligação entre os processos de justificação e descoberta, a justa utilização devida de cada um destes domínios, de forma e nos momentos adequados, que permite promover o conhecimento (Feyerabend, 1975).

O segundo exemplo é mais pessoal. Surgiu ao dar banho à minha filha de 15 meses, na banheira onde habitualmente brinca com vários brinquedos. Entre estes, apercebi-me que ela deu o mesmo nome, "pato", a três brinquedos diferentes, com tamanhos, formas e cores dissemelhantes mas, efectivamente, pretendem representar a mesma coisa: um pato! Esta situação banal do nosso quotidiano remeteu-me para Husserl. Como é que a consciência subjectiva, já presente numa criança de 15 meses, consegue saber apesar das diferenças entre três objectos, que estes representam a mesma coisa? Como é que a subjectividade da minha filha consegue ser objectiva? Arriscaríamos a dizer que na sua ingenuidade, ela consegue algo que alguns investigadores tendem a confundir.

Não se trata tanto de defender uma dicotomia entre o subjectivo e o objectivo, mas de criar com a sua subjectividade uma certa objectividade, melhor dizendo, um consenso intersubjectivo, já que, também a mim, na minha subjectividade, aqueles objectos me parecem representar patos! Não foi este um dos desafios a que Husserl se lançou? Estudar como pode a consciência humana, iminentemente subjectiva e intencional, produzir conhecimento de concordância intersubjectiva? Ou como referiu logo no foreword de "Logical Investigations", se viu cada vez mais inclinado a reflectir "on the relationship, in particular, between the subjectivity of knowing and the objectivity of the content known" (Husserl, 1900/2001).

Trata-se de uma ruptura epistemológica fundamental introduzida pela fenomenologia, ao desnaturalizar a consciência, cria uma distinção crucial com a visão empírica dos actos de consciência. Precisamente, porque a consciência é intencional, visa sempre um objecto intencional, não redutível às leis espaço - temporais ou causais do empirismo, colocando-nos assim ao nível do sentido. A distinção entre conteúdos reais e conteúdos ideais, permitiu compreender como é que uma multiplicidade de actos de consciência, empiricamente distintos, pudessem visar um e mesmo objecto, tal como aconteceu no exemplo dos três patos.

O que importa aqui salientar, sem entrarmos com pormenor na fenomenologia husserliana, são alguns aspectos que podem ajudar ao diálogo estabelecido por este texto.
Foi precisamente pelo facto de Husserl, desde cedo, se movimentar nos domínios da subjectividade e da objectividade, das relações entre ambos, que a fenomenologia introduz a noção de intencionalidade, ultrapassando as limitações da naturalização da consciência e permitindo validar o significado e a objectividade dos actos de consciência subjectivos. Posteriormente, a fenomenologia poderia amadurecer, para se situar como teoria geral do conhecimento.

Não queremos com este exemplo defender que Husserl seja a última voz, ou que represente a verdadeira e correcta fenomenologia, apenas salientar um dos maiores contributos, não apenas do autor, mas de todo o movimento fenomenológico, ao introduzir uma ruptura epistemológica fundamental no conhecimento contemporâneo. Ruptura essa que nos parece ir muito além de algumas posições reducionistas, muito em voga actualmente, que pretendem posicionar a fenomenologia numa posição subjectivista extrema, que só iria conduzir a um relativismo céptico, visto que no limite, as nossas metodologias de investigação, o nosso conhecimento, perderiam o carácter comum e a dimensão ética que deve ligar os homens e as civilizações.

Curiosamente, já em 1900, Husserl combatia, ainda que num contexto diferente, os perigos do relativismo individual. Já no "Prolegomena to pure logic", volume I das "Logical Investigations", Husserl (1913) vai situar-se numa posição que lhe permite observar, distante e criticamente, o terreno da discussão epistemológica do seu contexto cultural e científico. Esgrimiam-se argumentos a favor do psicologismo - a lógica seria um ramo da psicologia -, onde estavam homens como Mill, Spencer, Lipps, os antipsicologistas por sua vez, representados pelos neokantianos, pretendiam demonstrar que, enquanto que a psicologia explica como é o pensar, a lógica, por seu lado, pretendia clarificar como deve ser o pensar. Husserl critica ambos os lados, desenvolve uma obra argumentativa notável a todos os níveis, logo no início do "Prologomena", alertou para o perigo que poderia causar à Lógica do seu tempo o facto de haver uma "misinterpretation of theorethical principles, and the consequent confusion of fields, progress in logical knowledge has been gravely hindered" (Husserl, 1900/2001, p. 13).

\section{(In) Conclusões}

O nosso argumento é que o mesmo tipo de problema se passa hoje na fenomenologia. Não apenas se empurra a fenomenologia a dar cobertura a posições teóricas e metodológicas que não estão de acordo com os seus princípios basilares, como se promove uma confusão entre domínios de conhecimento, não permitindo a correcta clarificação de teorias e metodologias, resultando no nosso entender, não num aumento de conhecimento socialmente válido, porque partilhável, mas antes inconsequente. Em 
boa verdade, liberdade, não é número ilimitado de possibilidades, pelo contrário, é necessidade de escolhas, ou mesmo é dizer, exclusão de possibilidades e não possibilidade infinitas. Parece-nos, pelas razões expostas, haver a necessidade de promover uma clarificação dos conceitos fenomenológicos e sua aplicação ao contexto de investigação. Aprofundar e desenvolver metodologias de investigação existentes, em contraponto ao contexto actual da investigação qualitativa actual, mais apostada em acreditar na perspectiva que a criação de um cada vez maior número de metodologias de investigação, ser o caminho mais adequado e eficaz para construir conhecimento inter subjectivo.

\section{Referências Bibliográficas}

Casement, P. (1985). On learning from the patient. London: Routledge.

Colaizzi, P. F. (1978). Psychological Research as the Phenomenologist Views It. In R. S. Valle, \& King. Existential-phenomenological alternatives for psychology. New York: Oxford University Press.

Feyerabend, P. (1975). Contra o método. Lisboa: Relógio d'Água.

Gadamer, H. G. (1960/2003). Truth and method. New York: Seabury Press.

Gadamer, H. G. (1976). Philosophical hermeneutics. Los Angels: University of Califórnia Press.

Giorgi, A. (1985). Phenomenological and psychological research. Pittsburgh: Duquesne University Press.

Heidegger, M. (1927/1962). Being and time. Oxford: Basil Blackwell.

Husserl, E. (1900/2001). Logical investigations. Oxon: Routledge.

Husserl, E. (1913) Ideas pertaining to a pure phenomenology and to a phenomenological philosophy: first book. Dordrecht: Kluwer.

Karlsson, G. (1995). Psychological qualitative research from a phenomenological perspective. Goteborg: Graphic Systems.

Moustakas, C. (1994). Phenomenological research methods. London: Sage.

Smith, J. A. \& Osborn, M. (2003). Interpretative phenomenological analysis. In J. Smith (Ed.). Qualitative psychology: a practical guide to research methods. London: Sage.

Spinelli, E (2006), The value of relatedness in existential psychotherapy and phenomenological enquiry. The Indo-Pacific Journal of Phenomenology, 6.

Van Kaam, A. (1966). Existential foundations of psychology. Pennsylvania: Dimension Books.
Van Manen, M. (1990). Researching lived experience. New York: Sunny

Willing, C. (2001). Introducing qualitative research in psychology: adventures in theory and method. Buckingham: Open University Press.

Daniel Sousa - Professor Assistente Convidado do Instituto Superior de Psicologia Aplicada (ISPA - Lisboa, Portugal), Membro da Unidade de Investigação de Psicologia e Saúde (Instituto Superior de Psicologia Aplicada). Doutorando em Psicologia no Reggent's College (School of Psychotherapy and Counselling, London and Whales University, UK). Psicoterapeuta registrado na Society for Existential Analysis, London e UKCP - United Kingdom Council for Psychotherapy, UK. Endereço para correspondência: ISPA (Mestrado em Relação de Ajuda) - Rua Jardim do Tabaco, 34 - 1149.041 - Lisboa. Email: <daniel.sousa@ispa.pt>

Recebido em 28.06.08 Aceito em 10.08.08 